\title{
SERAPAN KOSAKATA BAHASA ARAB MEMPENGARUHI BUDAYA \\ ISLAM BATAK ANGKOLA-MANDAILING
}

\author{
Oleh: \\ Husniah Ramadhani Pulungan
}

\begin{abstract}
Islamic culture of Batak Angkola Mandailing (BAM) is influenced by vocabulary absorption of Arabic Language. History has mentioned that Arabic language brought by Arabic, Gujarat and Persian merchant in order to spread Islam.

The vocabulary absorption of Arabic language has happened because there is no match vocabulary or word in BAM and to help the society to communicate and avoid the misunderstanding among them.

Moreover, the society of BAM used it actively and becomes the part of their culture in daily communication.
\end{abstract}

\section{Keyword: Absorption, Vocabulary, Arabic Language, Islamic Culture, Batak Angkola-Mandailing.}

\section{A. Pendahuluan}

Sebagai alat perhubungan, bahasa Indonesia mampu memperhubungkan bangsa Indonesia yang berlatar belakang sosial budaya dan bahasa ibunya yang berbeda-beda. Berkat bahasa nasional, suku-suku bangsa yang berbeda bahasa ibunya itu dapat berkomunikasi dengan lancar dan akrab. Dengan modal bahasa Indonesia, setiap orang dapat menjelajah seluruh negara Republik Indonesia tanpa hambatan komunikasi. Dalam kedudukannya sebagai bahasa negara, bahasa Indonesia juga berfungsi sebagai pemerkaya bahasa dan sastra daerah. Hal ini karena bahasa daerah berfugsi sebagai lambang kebanggaan daerah, lambang identitas daerah, alat perhubungan di dalam keluarga dan masyarakat daerah, sarana pendukung budaya daerah dan bahasa Indonesia, serta pendukung sastra daerah dan sastra Indonesia. ${ }^{1}$ Salah satu bahasa daerah yang menarik untuk dianalisis adalah bahasa Batak. Hal ini karena masih

\footnotetext{
${ }^{1}$ Bustanul Arifin, Bahasa Bantu (Jakarta: Universitas Terbuka, 2010), h. 1.8-1.9
} 
langka tulisan yang berkaitan dengan bahasa Batak jika dikaitkan dengan dari mana asal-muasal bahasa serapannya. Bahasa yang akan dikaitkan dengan bahasa Batak kali ini adalah bahasa Arab.

Bahasa Arab merupakan bahasa yang berasal dari Tanah Arab atau daerah Timur Tengah. Bahasa Arab termasuk kelompok bahasa Semit, seperti halnya juga bahasa Akkadia (Babylonia dan Assyria), Ugaritik, Ibrani, Funisia, Syria, Ethiopia, Arabia Seltan, dan banyak dialek Arab lainnya. Sejak dahulu kala, catatan sejarah mengungkapkan bahwa tempat asal usul bahasa Seit adalah suatu wilayah yang berdekatan dengan kawasan Bulan Sabit Subur (Fertile Cresent), Semenanjung Arab dan Ethiopia. Bahasa Arab dan bahasa Ethiopia merupakan dua unsur bahasa utama dari pembagian geografis ini.

Bahasa Arab sendiri dapat dibagi menjadi dialek-dialek selatan dan dialek-dialek utara. Pasasti-prasasti tertua dalam dalam bahasa Arab Selatan dapat ditelusuri sejak abad ke-8 sebelum masehi, bahasa Arab Utara muncul belakangan. Baru pada abad ke-6 masehi didapatkan informasi bahasa Arab yang nampaknya telah berkembang menjadi bahasa Alquran pada abad berikutnya. Inilah bahasa Arab yang sering disebut bahasa Arab fusha pada masa Islam yang akan dianalisis pada tulisan kali ini. ${ }^{2}$

Kemudian, bahasa Arab dikenal dalam budaya Batak, tentu tidak luput dari perkembangan sejarah. Pada abad ke-14, para pedagang dari Persia dan Gujarat datang ke Malaka. Di samping mereka berdagang, juga menyebarkan Agama Islam. Dengan demikian, bahasa Melayu (lingua franca) sangat dipengaruhi oleh Persia dan Arab dalam kesustraan dan kosakatanya. Apabila bahasa Melayu saja sudah banyak mendapat pengaruh dari bahasa Arab, tentu saja hal ini juga akan dialami oleh bahasa Batak, mengingat penyebaran Islam terus

\footnotetext{
${ }^{2}$ Ibid, h. 7.5
} 
dilakukan di sepanjang Pulau Sumatera pada waktu itu dengan berbagai daya dan upaya.

Kemudian, mengenai asal-usul aksara Batak dapat dijelaskan dari paleografi yaitu ilmu tentang tulisan-tulisan kuno. Di banyak masyarakat yang mengenal tulisan terdapat naskah-naskah kuno yang umurnya dapat mencapai ratusan bahkan ribuan tahun. Aksara yang terdapat pada naskah-naskah kuno pada umumnya berbeda dengan aksara yang terdapat dalam naskah yang lebih baru. Dengan cara memperbandingkan aksara-aksara yang terdapat dalam naskahnaskah lama, maka akan dapat disusun semacam silsilah aksara.

Sebagian besar sistem tulisan yang ada di Afrika, eropa, dan Asia berasal dari satu sumber, yakni Aksara Semit Kuno yang menjadi nenek moyang tulisan-tulisan Asia (Arab, Ibrani, dan India) maupun Eropa (Latin, Yunani, dan sebagainya).

Aksara Batak termasuk keluarga tulisan India. Aksara India yang tertua adalah aksara Brahmi yang menurunkan dua kelompok tulisan yakni India Utara dan India Selatan. Aksara Nagari da Palawa masingmasing berasal dari kelompok utara dan selatan dan kedua-duanya pernah dipakai di berbagai tempat di Asia Tenggara, termasuk Indonesia. Adapun yang paling berpengaruh adalah aksara Palawa. Semua tulisan asli Indonesia berinduk pada aksara tersebut. ${ }^{3}$

Di antara aksara-aksara nusantara yang paling dekat dengan aksara Batak adalah aksara Kerinci (surat incung), aksara Lebong, Lembak, Lintang, Pasemah, Rejang, Serawai (surat ulu), serta aksara Lampung. Sama dengan daerah Batak, daerah-daerah tersebut juga agak terpencil di daerah pegunungan sehingga kurang terpengaruh oleh pengaruh-pengaruh asing yang dibawa dari seberang lautan dan secara lambat merembet dari pesisir ke pedalaman. Salah satu pengaruh budaya asing adalah masuknya agama Islam. Serentak dengan penyebaran agama Islam tersebar pula tulisan Arab yang di

${ }^{3}$ Uli Kozok, Surat Batak (Jakarta: Kepusatkaan Populer Gramedia, 2009), h. 63 
Melayu terkenal sebagai tulisan Jawi. Aksara “Arab gundul” tersebut cepat menggantikan aksara-aksara Sumatera asli yang kemudian hilang sama sekali. Karena daerah-daerah yang disebut di atas berada di pedalaman dan agak terpencil, maka pengaruh Islam baru dirasakan pada abad ke-19 sehingga aksara asli masih dapat bertahan sampai abad ke-20. Besar kemungkinan aksara Minangkabau dan Melayu juga pernah ada, tetapi kemudian digantikan oleh tulisan Arab-Melayu sehingga hilang tak berbekas ${ }^{4}$.

Surat Batak digunakan oleh proto-Batak Angkola-Mandailing, Toba, Simalungun, Pakpak-Dairi, dan Karo. Namun, yang akan dibahas di sini hanya hal-hal yang berkaitan dengan proto-Batak AngkolaMandailing saja. Hal ini karena dari sekian Proto-Batak, hanya Angkola-Mandailing yang memiliki pemeluk agama Islam yang mayoritas. Kenyataan ini tidak luput dari sistem bahasa yang mempengaruhi budaya kehidupan masyarakatnya. Dengan demikian, tulisan kali ini akan menguraikan serapan kosakata bahasa Arab mempengaruhi budaya Islam Batak Angkola-Mandailing. Hal ini bertujuan untuk melestarikan bangunan wawasan kebahasaan dan perkembangan sejarah kebahasaan nusantara.

\section{B. Pengertian}

Istilah-istilah yang berkaitan dengan tulisan ini akan diuraikan sebagai berikut.

\section{Pengertian Serapan}

Secara etimologis, serapan berarti (1) hasil menyerap (mengisap melalui liang-liang renik); yang diserap; (2) alat untuk menyerap; (3) lubang berisi ijuk dan sebagainya untuk tempat air kotoran. ${ }^{5}$ Proses penyerapan dalam bahasa Indonesia terdiri dari:

\footnotetext{
${ }^{4}$ Ibid, h. 67

${ }^{5}$ Hasan Alwi, dkk. Kamus Besar Bahasa Indonesia, ( Jakarta: Balai Pustaka, 2005), h. 1046
} 
a. Adopsi adalah serapan utuh tanpa perubahan atau penyesuaian. Unsur-unsur bahasa itu diserap sama dengan bentuk aslinya. Contoh:

$\begin{array}{lll}\text { Serapan } & \text { Bentuk Asli } & \text { Kata Lain } \\ \text { dawet } & \text { dhawet } & \text { dawat } \\ \text { ruwet } & \text { ruwet } & \text { ruwat } \\ \text { sumber } & \text { sumber } & \text { sumbar } \\ \text { seret } & \text { seret } & \text { serat } \\ \text { ulet } & \text { ulet } & \text { ulat }\end{array}$

b. Adaptasi adalah serapan yang disesuaikan dengan kaidah bahasa Indonesia, yang meliputi kaidah ejaan, pembentukan kata, dan kalimat. Penyesuaian itu perlu dilakukan dengan tujuan untuk membina, menumbuhkan, dan mengembangkan bahasa Indonesia. Contoh:

\section{Bahasa Jawa}

trampil

kripik

grobag

bedhug

gubug

\section{Bahasa Indonesia}

terampil

keripik

gerobak

beduk

gubuk

c. Penghibridaan merupakan penyepadanan dari unsur asing ke unsur bahasa Indonesia. Contoh:
Dasar
Imbuhan Hibrida
Asing Indonesia penstandaran
Indonesia Asing sengonisasi
Kemudian, contoh katanya adalah:
modernisasi $\rightarrow$ pemodernan
legalisasi $\rightarrow$ pelegalan
lelenisasi $\rightarrow$ perlelean
produktivitas $\rightarrow$ keproduktifan
efektivitas $\rightarrow$ keefektifan
stabilisasi $\rightarrow$ penstabilan 
d. Serapan terjemahan yaitu serapan yang dihasilkan dengan menerjemahkan kata/istilah asing tanpa mengubah konsep maknanya. Contoh:

1) Terjemahan langsung, misalnya: upgrading 'penataran'

2) Terjemahan dari serapan adopsi, misalnya: editorial 'tajuk rencana'

3) Terjemahan dari serapan adaptasi, misalnya: deskripsi 'perian'

4) Terjemahan dari serapan hibrida, misalnya: mengedit 'menyunting'

\section{Pengertian Kosakata}

Kosakata merupakan semua kata yang terdapat dalam suatu bahasa. Dalam hal kosakata bahasa Indonesia, maka yang disebut kosakata bahasa Indonesia adalah semua kata yang ada dalam bahasa Indonesia seperti yang didaftarkan di dalam kamus-kamus bahasa Indonesia. Berapa banyak kata yang terdapat di dalam bahasa Indonesia tidak dapat disebutkan jumlahnya dengan pasti, sebab kata-kata itu merupakan bagian dari sistem bahasa yang sangat rentan terhadap perubahan dan perkembangan sosial budaya masyarakat, sehingga jumlahnya sewaktu-waktu bisa bertambah maupun berkurang. Di samping itu, konsep tentang apakah kata itu juga menjadi masalah dalam penghitungan banyaknya kata dalam bahasa Indonesia. Bentuk luar negeri terdiri dari sebuah kata atau dua buah kata, masih bisa dipersoalkan. Begitupun bentuk segitiga sama kaki apakah terdiri dari sebuah kata atau empat buah kata. Dalam kajian gramatika juga masih bisa dipersoalkan bentuk-bentuk seperti menulis, ditulis, dan tertulis, apakah tiga buah kata yang berbeda ataukah hanya sebuah kata yang secara inflektif digunakan dalam modus kalimat yang berbeda.

Kemudian, kata-kata yang dikuasai oleh seseorang atau sekelompok orang dari lingkungan yang sama, maka dalam hal ini dapat dilihat bahwa kata-kata yang dikuasai oleh si A, tidak sama banyaknya dengan yang dikuasai oleh si $\mathrm{B}$, atau si $\mathrm{C}$. Begitu juga 
jumlah kata yang dikuasai oleh anak SD kelas III tidak akan sama dengan yang dikuasai oleh anak SD kelas V, atau anak SLTP kelas II.

Di satu sisi, kata-kata atau istilah yang digunakan dalam suatu bidang kegiatan atau ilmu pengetahuan. Misalnya, kata-kata yang digunakan dalam bidang olahraga, bidang ekonomi, bidang hukum, dan bidang musik. Di sisi lain, sejumlah kata dari suatu bahasa yang disusun secara alfabetis beserta dengan sejumlah penjelasan maknanya, layaknya sebagai sebuah kamus.

Sementara itu, semua morfem yang ada dalam suatu bahasa memberikan pengertian bahwa kosakata bukan hanya yang secara gramatikal disebut kata (morfem dasar atau bentuk bebas lainnya), tetapi juga termasuk morfem-morfem terikat lainnya. Dengan demikian, konsep-konsep tentang kosakata terlihat luas dan beragam ${ }^{6}$.

\section{Bahasa Arab}

Bahasa Arab kini menjadi alat komunikasi bagi sekitar seratus juta orang. Pada Abad Pertengahan, selama ratusan tahun bahasa Arab merupakan bahasa ilmu pengetahuan, budaya, dan pemikiran progresif di seluruh wilayah dunia yang beradab. Antara abad ke-9 dan ke-12, semakin banyak karya filsafat, kedokteran, sejarah, agama, astronomi, dan geografi ditulis dalam bahasa Arab dibandingkan dengan bahasa-bahasa lain. Bahkan hingga kini bahasa-bahasa Eropa Barat masih memperlihatkan adanya pengaruh bahasa Arab dalam berbagai kata serapannya. Di samping aksara Latin, alfabet Arab merupakan sistem yang paling banyak digunakan dalam bahasa Persia, Afganistan, Urdu, sejumlah bahasa Turki, Berber, dan Melayu.

Dulu, bahasa ini juga digunakan oleh orang-orang Babilonia, Kaldea, Hitti, dan Phoenisia meski kini tidak ada lagi. Orang Arab dan orang-orag yang berlisan Arab masih, dan akan tetap ada.

\footnotetext{
${ }^{6}$ Abdul Chaer, Leksikologi dan Leksikografi Indonesia (Jakarta: Rineka Cipta, 2007), h. 6-8
} 
Seperti halnya di masa lalu, kini mereka mendiami wilayah geografis paling strategis yang meliputi salah satu jalur perdagangan tersibuk di dunia 7 .

Antara pertengahan abad ke-8 dan ke-13 orang-orang yang berbicara dengan bahasa Arab adalah para pembawa obor kebudayaan dan peradaban penting yang menyeruak menembus seluruh pelosok dunia ${ }^{8}$. Ada beberapa aspek yang bisa menjadi petunjuk terhadap perkembangan kebudayaan literer secara umum pada periode Umayyah, di antaranya pidato, korespondensi, dan puisi. Dengan demikian, maka dapat dinyatakan bahwa bahasa Arab adalah bahasa yang membawa peradaban bagi berbagai bangsa.

\section{Budaya Islam}

Islam adalah agama yang mencakup segala segi kehidupan manusia, baik kehidupan dunia maupun kehidupan akhirat. Agama Islam sangat menghargai amal saleh manusia, dan mendorong manusia berpikir kreatif. Sebab dengan beramal saleh dan berpikir kreatif, serta bekerja keras, manusia akan mendapat ganjaran yang baik di surga. Adapun ajaran Islam yang mendorong manusia atau masyarakat untuk berperadaban tinggi antara lain karena9:

a. Islam sangat menghargai akal, meletakkan akal pada tempat terhormat, memerintahkan manusia mempergunakan akalnya untuk memeriksa dan memikirkan keadaan alam (S. Ali Imran:189-190).

b. Islam mewajibkan setiap laki-laki dan perempuan pemeluk Islam untuk menuntut ilmu (S. Al-Mujadalah:11).

c. Islam melarang orang bertaklid buta, menerima sesuatu sebelum diperiksa (S. Al-Isra':36).

${ }^{7}$ Philip K. Hitti, History of The Arabs Edisi Revisi ke-10 (New York: Palgrave McMillan, 2002),

${ }^{8}$ Ibid, h. 708

${ }^{9}$ Murodi, Sejarah Kebudayaan Islam (Semarang: PT Karya Toha Putra, 1997), h. 23-24 
d. Islam mengerahkan pemeluknya supaya selalu menggali barangbarang penemuan yang belum ada, membuat inisiatif atau prakarsa, dan memberi manfaat bagi kemanusiaan.

e. Islam memerintahkan para pemeluknya untuk mencari keridhaan Allah dengan semua nikmat yang telah diterimanya, dan menyuruh mempegunakan hak-hak atas keduniaan dalam pimpinan dan peraturan agama (S. Al-Qashash:77).

f. Islam menggemarkan para pemeluknya supaya pergi meninggalkan kampung halamannya, berjalan ke negeri lain, memperhubungkan silaturahmi dengan bangsa dan golongan lain, saling bertukar pengetahuan, pandangan, dan perasaan (S. Al-Hajj:46).

g. Islam menyuruh memeriksa kebenaran walaupun datangnya dari kaum yang berlainan bangsa dan berlainan kepercayaan (S. Thaahaa:17).

\section{Batak}

Batak merupakan salah satu suku yang terdapat di provinsi Sumatera Utara. Pembagian tempat tinggalnya adalah sebagai berikut.

a. Di Kabupaten Tapanuli Utara terdiri dari:

1) Orang Batak Toba di Pulau Samosir (Pangururan), sekitar Danau Toba (Balige), Tanah Datar Humbang (Siborongborong), dan Lembah Silindung (Tarutung).

2) Orang Batak Dairi di tanah Pakpak dengan kota Sidikalang.

b. Di Wilayah Tabagsel(Kabupaten Tapanuli Selatan, Kabupaten Mandailing Natal, Kabupaten Paluta, Kabupaten Palas terdiri dari: Orang Batak Angkola, kota Padangsidimpuan, Kec. Sayurmatinggi, Kec. Sipirok, Kec. Batang Toru, Kecamatan Portibi, Sosa, Gunung Tua, Kec. Sorik Marapi, Panyabungan, Natal, dan Muara Sipongi. 
Dengan catatan, bahwa ada pihak yang kurang setuju memasukkannya ke dalam kelompok orang Batak. M. Hutauruk berpendirian bahwa mereka itu orang Batak yang nyata sekali dari sistem marganya (Nasution, Lubis), bahasanya yang tidak menimbulkan kesulitan bagi orang Batak Toba umpamanya dan adat-istiadatnya.

c. Di Kabupaten Tapanuli Tengah (Pesisir), pertemuan orang Batak Toba (mayoritas) dengan orang Batak Angkola dan orang pendatang dari luar suku Batak, hidup di daerah pantai dari Sibolga sampai Barus.

d. Di Kabupaten Karo, Sumatera Timur, orang Batak Karo (Kabanjahe).

e. Di Kabupaten Simalungun, Sumatera Timur, orang Batak Simalungun (Pematangsiantar).

Jadi, suku Batak mempunyai tujuh subsuku: Toba, Dairi, Angkola, Mandailing, Campuran, Karo, dan Simalungun. Jumlah anggota terbesarnya ialah subsuku Toba ${ }^{10}$. Adapun subsuku yang akan dibahas pada tulisan kali ini hanya pada Batak AngkolaMandailing (BAM) saja.

\section{C.Pembahasan}

Dalam pembahasan kali ini akan dipaparkan unsur-unsur serapan bahasa Arab yang masuk ke dalam Bahasa Batak AngkolaMandailing (BBAM). Unsur serapan yang dimaksud adalah kosakata utuh, kosakata Arab yang mengalami perubahan, kosakata bahasa Arab yang digunakan dalam BBAM, dan istilah, nama, dan semboyan dalam bahasa Arab sebagai berikut.

\section{Kosakata Utuh}

\footnotetext{
${ }^{10}$ M. Hutauruk, Sejarah Ringkas Tapanuli Suku Batak (Jakarta: Erlangga, 1987), h. 6
} 
Penyerapan kosakata utuh dari bahasa Arab ke BBAM terlihat dari kata yang terserap. Kata Arab yang terserap berupa kata dasar dan kata jadian sebagai berikut.

a. Kata Dasar

Kata dasar yang terserap secara penuh dapat dilihat pada contoh berikut.

$\begin{array}{ll}\text { adab } & \text { adab } \\ \text { badan } & \text { badan } \\ \text { jasad } & \text { jasad }\end{array}$

Contoh-contoh di atas menunjukkan bahwa kata-kata bahasa Arab diterima langsung ke dalam BBAM secara utuh. Kata $a d a b$, badan, dan jasad dalam bahasa Arab tetap menjadi adab, badan, dan jasad dalam BBAM.

b. Kata Jadian

Dalam bahasa Arab, kata dasar ditandai oleh tiga buah konsonan. Jika kata dasar itu akan dibentuk menjadi kata jadian, langkah yang dapat dilakukan adalah menambahkan fonem hamzah, mim, ta', nun, dan ya, atau fonem yang serupa dengan konsonannya. Bentuk kata jadian bahasa Arab yang diserap penuh ke dalam BBAM seperti terlihat dalam contoh-contoh berikut.

$\begin{array}{ll}\text { akbar } & \text { akbar } \\ \text { abjad } & \text { abjad } \\ \text { masjid } & \text { masojid }\end{array}$

\section{Kosakata Arab yang Mengalami Perubahan}

Selain menyerap kosakata utuh dari bahasa Arab seperti terlihat pada contoh-contoh sebelumnya, maka BBAM juga menyerap kosakata bahasa Arab dengan penyesuaian yang berupa penggantian fonem, penambahan fonem, dan penghilangan fonem. Semua perubahan itu dalam rangka penyesuaian dengan kaidah BBAM.

$\begin{array}{ll}\text { sabun } & \text { sabun } \\ \text { fasih } & \text { pasih }\end{array}$


khusus kusus

Contoh lain, kosakata Arab yang mengandung fonem /h/ jika masuk ke dalam bahasa Indonesia akan diganti fonem /h/.

$\begin{array}{ll}\text { hujjah } & \text { hujat } \\ \text { hikmah } & \text { hikmah }\end{array}$

Selain mengalami perubahan, kosakata Arab yang diserap oleh BBAM juga mengalami penambahan fonem. Sebagai contoh, kosakata bahasa Arab yang berpola KVKK umumnya kalau diserap ke dalam BBAM berubah menjadi dua suku dengan menambahkan vokal pada konsonan akhir.

$$
\begin{array}{ll}
\text { qalb } & \text { kolbu } \\
\text { waqt } & \text { waktu }
\end{array}
$$

Perubahan kosakata Arab yang diserap oelh BBAM juga bisa berupa penghilangan fonem. Sebagai contoh, kosakata Arab yang mengandung vokal panjang akan dihilangkan jka masuk ke dalam BBAM.

$$
\begin{array}{ll}
\text { lisaan } & \text { lisan } \\
\text { zamaan } & \text { jaman }
\end{array}
$$

Contoh lain, fonem / ...'./ dihilangkan

$$
\begin{array}{ll}
\text { 'aalam } & \text { alam } \\
\text { 'arif } & \text { arif }
\end{array}
$$

\section{Kosakata Bahasa Arab yang Digunakan dalam BBAM}

Bahasa Arab banyak memberikan sumbangan kosakata terutama di bidang agama Islam kemudian berintegrasi dengan BBAM dan menjadi bagian dari budaya Islam Batak Angkola-Mandailing. Contoh $^{11}$ :

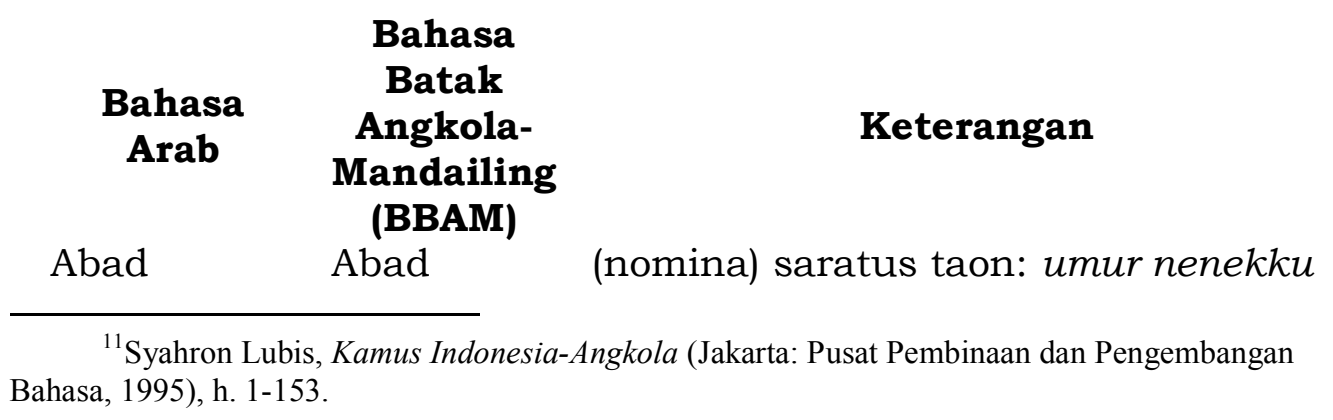


Adat

Adat

Adil

Amal

Amal

Arwah

Berkah

Doa

Dunia

Dunia

Fakir

Fana

Fitrah

Gaib

Hayat

Halal

Halal

Haram

Harom

Ikhlas

Ihlas hampir satu abad, 'umur ni ompungku hampir saratus taon'

(nomina) adat; kabiasoan: bangsa kita adalah bangsa yang terdiri dari banyak suku serta adat yang beragam, 'bangsonta on ima bangso na marasal sian suku na bahat asa adat na marmocom-mocom'; pada adatnya padoadatna; tahu adat mamboto adat; maradat

(adjektiva) Adil; mengadili

'mangadili'

Pengadilan 'pangadilan'

(nomina) parbuatan na deges dohot na jat; amal; amal maramal

(nomina) roh ni halak na mate: semoga arwahnya diterima Tuhan, 'mudahmudahan ditarimo Tuhan rohna'

(nomina) borkat; memberkati memborkati; keberkatan haborkatan

(nomina) doah; berdoa mandoah; mendoakan madoahkon: Ibu selalu mendoakan putra-putrinya agar berhasil, inang to do mandoah anso marhasil daganakna'

(nomina) dunia

(nomina) halak na lobi suada; kefakiran hasuadaan

(adjektiva) inda kokal: semua yang ada di dunia ini fana belaka, 'sude na adong di dunia on inda kokal'

(nomina) pitarah: menolak zakat fitrah kepada anak yatim, 'manulak pitarah tu anak yatim'

(nomina) goib; inda tarida mata: malaikat itu gaib, 'malokat i goib'

(nomina) ngolu: selama hayat dikandung badan, 'anggo laing mangolu'

(adjektiva) halal: makanan halal, 'panganon na halal'

(adjektiva) 1. Haram; 2. Na ias: tanah haram di Mekkah, 'tano na ias di Mokah'; uang haram 'epeng na so ias'; mengharamkan mangharomkon (adjektiva) dohot ate-ate na ias; mereka memberi pertolongan dengan ikhlas, 


\begin{tabular}{|c|c|c|}
\hline Ikhtiar & Ihtiar & $\begin{array}{l}\text { na ias'; mengikhlaskan 'mangihlaskon' } \\
\text { (nomina) usaho; berikhtiar marusaho; } \\
\text { mengikhtiarkan mangusahoon }\end{array}$ \\
\hline Imam & Imom & (nomina) imom \\
\hline Iman & Iman & (nomina) iman \\
\hline Izin & Isin & $\begin{array}{l}\text { (nomina) isin; halilisan; mengizinkan } \\
\text { patolahon; mangalehen isin }\end{array}$ \\
\hline Kabar & Habar & $\begin{array}{l}\text { (nomina) hobar; barita; kabar angin } \\
\text { hobar naso pasti; kabar baik hobar na } \\
\text { denggan; kabar buruk hobar na jat; } \\
\text { mengabarkan menghobarkon }\end{array}$ \\
\hline Maaf & Mohop & $\begin{array}{l}\text { (nomina) mohop: maaf saya datang } \\
\text { terlambat, 'mohop au ro parpudi'; } \\
\text { bermaaf-maafan }\end{array}$ \\
\hline & & $\begin{array}{l}\text { mohopan: pada hari lebaran mereka } \\
\text { bermaaf-maafan, ' di ari rayo halai } \\
\text { marsimohop-mohopan' }\end{array}$ \\
\hline Magrib & Magorip & $\begin{array}{l}\text { (nomina) magorip; mereka pulang dari } \\
\text { sawah menjelang magrib, 'donok } \\
\text { magorip ma halai mulak sian saba' }\end{array}$ \\
\hline Maklum & Maklum & $\begin{array}{l}\text { (adverbia) pohom; mangarti: saya } \\
\text { maklum akan hal itu, 'pohon do au tu } \\
\text { hal i'; memaklumkan paboahon anso } \\
\text { pohom }\end{array}$ \\
\hline Mesjid & Masojid & $\begin{array}{l}\text { (nomina) masojid: mesjid itu besar } \\
\text { sekali, 'masojid i na lobi godang' }\end{array}$ \\
\hline Musyawarah & Musawarat & $\begin{array}{l}\text { (nomina) pokat; bermusyawarah } \\
\text { marpokat; } \\
\text { mamokatkon }\end{array}$ \\
\hline Nasihat & Nasehat & (nomina) sipaingot; menasehati \\
\hline Paham & Pohom & $\begin{array}{l}\text { mangalehen sipaingot; paingotkon } \\
\text { (nomina) 1. Pangartian; } 2 \text {. Pandapot; } 3 . \\
\text { Aliran; memahami mangarti; sepaham } \\
\text { sapandapot }\end{array}$ \\
\hline Pikir & Pikir & $\begin{array}{l}\text { (nomina) pikir; berpikir marpikir; } \\
\text { berpikir-pikir; } \\
\text { mamikirkon; pikiran pikiran }\end{array}$ \\
\hline Rela & Rela & $\begin{array}{l}\text { (adjektiva) marsadio dohot ias ni roha; } \\
\text { ra: }\end{array}$ \\
\hline Rujuk & Rujuk & $\begin{array}{l}\text { (verba) mulak tu dadaboru na madung } \\
\text { ipaulak; ia telah rujuk kembali kepada } \\
\text { isterinya, 'madung rujuk ia mulak tu } \\
\text { dadaboru nia i' }\end{array}$ \\
\hline Sabar & Sobar & $\begin{array}{l}\text { (adjektiva) } 1 . \text { Sobar; 2. Inda sosakan; } \\
\text { bersabar marsabar; menyabarkan } \\
\text { manyobarkon; penyabar panyobar }\end{array}$ \\
\hline
\end{tabular}




\begin{tabular}{|c|c|c|}
\hline Selamat & Selamat & $\begin{array}{l}\text { (adjektiva) horas; salamat; inda } \\
\text { marbahaya: selamat sampai tujuan, } \\
\text { 'aman sampe tu na ituju'; selamat } \\
\text { berjumpa horas; selamatan horja } \\
\text { mangido hasalamatan }\end{array}$ \\
\hline Syukur & Sukur & $\begin{array}{lccc}\text { (nomina) } & \text { tarimokasi } & \text { tu } & \text { Tuhan; } \\
\text { bersyukur } & \text { marsukur; } & \text { mensyukuri } \\
\text { mansukuri } & & \end{array}$ \\
\hline Tertib & Tertib & $\begin{array}{l}\text { (adjektiva) taratur; menertibkan } \\
\text { mangatur }\end{array}$ \\
\hline Wajib & Wajib & $\begin{array}{l}\text { (verba) musti; wajib belajar daganak na } \\
\text { marumur } 7-12 \text { taon musti sikola; wajib } \\
\text { militer musti masuk dinas tentera } \\
\text { muda iporluhon pamorenta; wajib } \\
\text { pajak mustik mambayar pajak; } \\
\text { berwajib musti mangurus; kewajiban } \\
\text { kewajiban; sewajibnya sapatutna; } \\
\text { samustina }\end{array}$ \\
\hline Wafat & Wapat & (verba) maninggal; jumolo \\
\hline Zakat & Sokat & omina) \\
\hline
\end{tabular}

\section{Istilah, Nama, dan Semboyan dalam Bahasa Arab}

a. Istilah

$$
\begin{aligned}
& \text { Akhirat = alam setengah kehidupan di dunia; alam baka } \\
& \text { Akidah = kepercayaan dasar; keyakinan pokok } \\
& \text { akil balig = tahu membedakan baik dan buruk (laki-laki } \\
& \text { berumur } 15 \text { tahun ke atas); cukup akalnya. } \\
& \text { Khotbah = pidato terutama untuk memurnikan ajaran agama } \\
& \text { Istikharah = salat sunah memohon ditunjukkan pilihan yang } \\
& \text { benar } \\
& \text { Yatim = tidak berayah atau tidak beribu lagi karena ditinggal } \\
& \text { mati. } \\
& \text { Azan = seruan untuk mengajak orang melakukan salat. } \\
& \text { Rujuk = kembalinya suami kepada istrinya yang ditalak, } \\
& \text { talak satu atau talak dua, ketika istri masih } \\
& \text { di masa iddah. }
\end{aligned}
$$


b. Nama
1) Ruhulkudus = gelar malaikat Jibril
2) Ahlinujum =ahli perbintangan
3) Alkadim = Yang Mahadahulu (Allah)
4) Almasih = yang diselamatkan (Gelar Nabi Isa a.s.)
5) Alquran = nama kitab suci umat Islam
6) Mikail = nama malaikat pembagi rezeki
7) Yahudi= nama bangsa
8) Jin = nama makhluk halus yang diciptakan dari api
9) Malaikatulmaut= gelar malaikat Izrail

c. Semboyan

Semboyan dari bahasa Arab yang juga digunakan dalam BBAM terdiri dari:

1) Innalillahi wa inna ilaihi raji'un artinya "Sesungguhnya kita kepunyaan Allah dan sesungguhnya kita kembali kepada-Nya" (biasanya diucapkan manakala kita mendapat musibah).

2) Alhamdulillah artinya "Segala puji bagi Allah" (ungkapan dipakai manakala kita mendapat anugerah Tuhan).

3) Astagfirullah artinya "Semoga Allah mengampuni aku" (seruan untuk menyatakan heran bercampur sedih).

4) Assalamualaikum artinya "Keselamatan/kesejahteraan bagimu" (biasanya diucapkan pada awal dan akhir pidato, saat bertemu dengan seseorang, dsb.).

5) Bismillah artinya "Dengan nama Allah" (ungkapan yang diucapkan ketika kita memulai suatu pekerjaan).

6) Insya Allah artinya "Jika Allah mengizinkan" (ungkapan yang digunakan untuk menyatakan harapan atau janji yang belum tentu dipenuhi).

7) Laknatullah artinya "Semoga Allah mengutuk".

8) La ilaaha illallah artinya "Tiada Tuhan selain Allah". 
Berdasarkan pemaparan di atas, maka dapat dijelaskan bahwa penyerapan kosakata bahasa Arab yang digunakan dalam BBAM otomatis mempengaruhi kehidupan budaya masyarakat BAM sendiri. Pengaruh Islam yang kental berasal dari kosakata yang digunakan. Seperti salah satu fakta dalam ilmu psikolinguistik yaitu bahasa memengaruhi perilaku menyebabkan budaya Islam terintegrasi dalam kehidupan BAM. Dengan demikian, masyarakat BAM dengan sendirinya ingin mengetahui lebih banyak hak-hal yang berkaitan dengan kosakata tersebut sehingga kehidupannya (dalam hal ini kehidupan spritual) semakin membaik setiap harinya.

\section{D.Penutup}

Tulisan ini menguraikan serapan kosakata bahasa Arab mempengaruhi budaya Islam Batak Angkola-Mandailing. Hal ini bertujuan untuk melestarikan bangunan wawasan kebahasaan dan perkembangan sejarah kebahasaan nusantara. Unsur-unsur serapan bahasa Arab yang masuk ke dalam Bahasa Batak Angkola-Mandailing (BBAM) adalah kosakata utuh, kosakata Arab yang mengalami perubahan, kosakata bahasa Arab yang digunakan dalam BBAM, dan istilah, nama, dan semboyan dalam bahasa Arab. Penyerapan kosakata bahasa Arab yang digunakan dalam BBAM otomatis mempengaruhi kehidupan budaya masyarakat BAM sendiri. Pengaruh Islam yang kental berasal dari kosakata yang digunakan. Seperti salah satu fakta dalam ilmu psikolinguistik yaitu bahasa memengaruhi perilaku menyebabkan budaya Islam terintegrasi dalam kehidupan BAM. Dengan demikian, masyarakat BAM dengan sendirinya ingin mengetahui lebih banyak hak-hal yang berkaitan dengan kosakata tersebut sehingga kehidupannya (dalam hal ini kehidupan spritual) semakin membaik setiap harinya. 


\section{Daftar Pustaka}

Arifin, Bustanul. Bahasa Bantu, Jakarta: Universitas Terbuka, 2010.

Kozok, Uli. Surat Batak, Jakarta: Kepusatkaan Populer Gramedia, 2009.

Alwi, Hasan. dkk. Kamus Besar Bahasa Indonesia, Jakarta: Balai Pustaka, 2005.

Chaer, Abdul. Leksikologi dan Leksikografi Indonesia, Jakarta: Rineka Cipta, 2007.

Hitti, Philip K. History of The Arabs Edisi Revisi ke-10, New York: Palgrave McMillan, 2002.

Murodi, Sejarah Kebudayaan Islam, Semarang: PT Karya Toha Putra, 1997.

Hutauruk, M. Sejarah Ringkas Tapanuli Suku Batak, Jakarta: Erlangga, 1987.

Lubis, Syahron. Kamus Indonesia-Angkola, Jakarta: Pusat Pembinaan dan Pengembangan Bahasa, 1995. 